\title{
Lymphoid Apoptosis in Acute Canine Distemper
}

\author{
Kazuyoshi KUMAGAI ${ }^{1)}$, Ryoji YAMAGUCHI ${ }^{1)}$, Kazuyuki UCHIDA ${ }^{1)}$ and Susumu TATEYAMA ${ }^{1)}$ \\ ${ }^{1)}$ Department of Veterinary Pathology, Faculty of Agriculture, Miyazaki University, Miyazaki 889-2192, Japan
}

(Received 23 June 2003/Accepted 2 October 2003)

ABSTRACT. The relationship between the canine distemper virus (CDV) infection and apoptosis in the canine lymphoid tissues was investigated using immunostaining for single stranded DNA (ssDNA), TdT-mediated dUTP-biotin nick end-labeling (TUNEL) method, and electron microscopy. Twenty-six lymphoid tissues from 8 spontaneously CDV-infected dogs and 1 non-infected dog were used, and lesions were classified into 4 groups according to frequency of the CDV-antigen. Histologically, the degree of lymphoid depletion tended to depend on amount of CDV antigen. The numbers of ssDNA- and TUNEL-labeling cells were significantly high in the lymphoid tissues with abundant viral antigen. However, ssDNA- and TUNEL-positive lymphocytes were also frequently found even in the lymphoi $\mathrm{d}$ tissues where there was only a small amount of CDV-antigen in sinus histiocytes. The incidence and distribution of apoptotic cells in the CDV-antigens-negative lymphoid tissues from infected dogs were equal to those from a non-infected dog. Double labeling immunostaining using a ssDNA and a CDV nucleocapsid protein (CDV-NP) antibody revealed that there were ssDNA positive but CDV-NP negative cells besides those stained doubly positive. Ultrastructurally, lymphocytes in the CDV-infected lymphoid tissues frequ ently had characteristic morphological features of apoptosis such as apoptotic bodies. All these results suggest that CDV leads to lymphocytic apoptosis directly or indirectly, resulting in severe lymphoid depletion and immunosuppression in acute or subacute phase of CDV in fection. KEY WORDS: apoptosis, canine distemper virus, immunosuppression, ssDNA, TUNEL method.

J. Vet. Med. Sci. 66(2): 175-181, 2004

Canine distemper virus (CDV), genus morbillivirus, family paramyxoviridae, infects young dogs through several routes such as aerosol or droplet infection and contacts the epithelium of the upper respiratory tracts $[8,23] . \mathrm{CDV}$ is replicated in macrophages and lymphocytes of the upper respiratory tracts and disseminated to systemic lymph nodes and various organs including the spleen, thymus, bone marrow and gastrointestinal lymphoid tissues [8]. It has been widely known that CDV causes severe persisting immunosuppression with lymphoid depletion during or after an acute infection, resulting in bronchopneumonia due to secondary bacterial infections, acute non-suppurative encephalitis, and subchronic demyelinating leukoencephalitis [15, 25, 27].

The pathogenesis of immune suppression due to CDV remains unclear. It has been supposed that CDV may be replicated in the immunocompetent cells, especially the CD4+ T cells during acute phase, resulting in lymphopenia $[11,31]$. Also it has been recognized that CDV induces lymphopenia without a significant decrease of neutrophils, eosinophils and monocytes [18]. Moreover, lymphoid depletion by acute CDV infection may recur in the course of the chronic phase, but immunocompetent in lymphoid tissues after the elimination of the virus does not turn out completely $[14,15]$.

The measles virus (MV), which is related closely to CDV $[8,23]$, is also known to cause severe immunosuppression during an acute infection among infants. Previous investigations have shown MV-induced apoptosis in monocytic and lymphocytic lineages could relate to immunosuppres-

\footnotetext{
* Correspondence to: Yamaguchi, R. Department of Veterinary Pathology, Faculty of Agriculture, Miyazaki University, Miyazaki 889-2192, Japan.
}

sion $[4,7,12,21,22]$. Likewise, apoptotic cell-death was also recognized in both CDV-infected Vero cells and inflammatory cells in chronic demyelinating encephalitis associated with CDV $[10,25]$. However, there have been limited reports to stress on the role of apoptotic cell-death in the CDV-infected lymphoid tissue to explain the lymphoid depression among infected dogs except for a recent report [19].

Morphologic features of apoptosis, which is called "programmed cell death", are defined as nuclear shrinkage and collapse, chromatin concentration, and formation of apoptotic body due to the fragmentation of DNA strands by an activated endogenous endonuclease [2]. As a role, the detection of fragmented DNA in the tissue sections has been used by the terminal deoxynucleotidyl transferase (TdT)mediated dUTP-biotin nick end-labeling (TUNEL) assay. Recently, the immunohistochemical method using an antisingle stranded DNA (ssDNA) antibody has been applied to detect apoptotic nuclei in situ [13, 28, 29]. This antibody specifically recognizes DNA 3'-OH ends, which are fragmented single-stranded DNA. Moreover it has been shown between the TUNEL assay and ssDNA-immunostaining correlate closely [28].

The aim of this study was to elucidate the relationship between the CDV infection and the apoptotic cell-death in the lymphoid tissues of infected dogs. The present paper discusses the role of CDV-associated apoptotic-cell-death on the pathogenesis of lymphoid depletion in infected dogs.

\section{MATERIALS AND METHODS}

Samples: Twenty-six lymphoid tissue samples including the tonsils, and mandibular, mediastinal, and mesenteric 
Table 1. Summary of the clinical feature and evidence for the CDV infections

\begin{tabular}{|c|c|c|c|c|c|}
\hline Breed & $\begin{array}{c}\text { Age } \\
\text { (months) }\end{array}$ & Sex & ELISA & $\begin{array}{l}\text { Immunohistochemically } \\
\text { CDV-NP positive tissues }\end{array}$ & $\begin{array}{c}\text { CDV antigen area } \\
\text { in lymphoid tissues (\%) }\end{array}$ \\
\hline Papillon & 8 & $\mathrm{M}$ & - & - & - \\
\hline Papillon & 4 & $\mathrm{~F}$ & $\mathrm{~B}+$ & cerebrum, cerebellum, lung + & 0 \\
\hline M. longdachshund & 2 & M & $\mathrm{P}+$ & cerebrum, cerebellum, lung + & $0,1.01$ \\
\hline Newfundland & 3 & M & $\mathrm{B} \pm$ & cerebrum, cerebellum, lung + & $15.4,7.2,7.4$ \\
\hline Labrador retriever & 2 & $\mathrm{M}$ & $\mathrm{B} / \mathrm{Sa} \pm, \mathrm{P} / \mathrm{S}+$ & cerebrum, cerebellum, lung + & $8.6,11$ \\
\hline Miniature dachshund & 2 & $\mathrm{M}$ & $\mathrm{B} \pm$ & cerebrum, cerebellum, lung + & $4.8,3.8,2.9$ \\
\hline Waimaranar & 2 & M & $\mathrm{B} / \mathrm{P} / \mathrm{S}+$ & cerebrum, cerebellum, lung + & $9,0.6,9$ \\
\hline Cavarier & 2 & M & $\mathrm{B}+$ & lung + & 0 \\
\hline Miniature dachshund & 3 & $\mathrm{M}$ & $\mathrm{B}+$ & cerebrum, cerebellum, lung + & $0.3,0.1,0.01$ \\
\hline
\end{tabular}

M, male; F, female; B, blood; P, pituita. Sa, saliva. S, stool.

lymph nodes were collected from 9 puppies having an acute or subacute CDV infection (Table 1). An immediate necropsy was performed after euthanasia in all dogs. Eight dogs were diagnosed as CDV infection by the detection of CDV antigens using a sandwich enzyme-linked immunosorbent assay (ELISA) (Adtec Inc, Ohita, Japan) from serum, pituita, stool and saliva, and the immunohistochemical methods on sections from the lungs, cerebrum and cerebellum. The remaining one had no evidence for CDV and was diagnosed as congenital hydrocephalus. All nine puppies were bred in a breeding company and vaccinated once or twice for CDV.

Histology: Tissue samples were fixed in $4 \%$ paraformaldehyde for $24 \mathrm{hr}$ at $4 \%$. Then, the samples were dehydrated through graded alcohols and embedded in paraffin. Serial sections of $4 \mu \mathrm{m}$ thick were mounted on sylancoated slides (Muto pure chemicals Co., Ltd, Tokyo, Japan) for routine pathological examination, immunohistochemistry and TUNEL methods.

Immunohistochemistry: Immunohistochemistry was performed with an Envision polymer reagent (DAKO-Japan, Kyoto, Japan). For the detection of CDV antigens, a monoclonal antibody against CDV nucleocapsid protein (CDVNP, 1:200, VMRD Inc. San Francisco, U.S.A.) was used. For the detection of apoptotic cells, a polyclonal antibody against ssDNA (1:200, DAKO-Japan) was used. For CDVNP-immunostaining, sections were autoclaved at $121^{\circ} \mathrm{C}$ for $5 \mathrm{~min}$. For ssDNA-immunostaining, sections were treated with Proteinase K (DAKO-Japan) for $1 \mathrm{~min}$ at a concentration of $400 \mu \mathrm{g} / \mathrm{ml}$ of $0.1 \mathrm{M}$ tris- $\mathrm{HCl}$ ( $\mathrm{pH} 7.5$ ). All sections were immersed into $3 \%(\mathrm{w} / \mathrm{v}) \mathrm{H}_{2} \mathrm{O}_{2}$ diluted in methanol for $10 \mathrm{~min}$ at room temperature to block the endogenous peroxidase activity, and then incubated with primary antibodies for CDV-NP or ssDNA at $37^{\circ} \mathrm{C}$ for $30 \mathrm{~min}$ followed by the Envision polymer reagent at $37^{\circ} \mathrm{C}$ for $30 \mathrm{~min}$. The reaction products were visualized with 3,3'-diaminobenzidine tetrahydrochloride (DAB). The sections for CDV-NP immunostain were counterstained with Mayer's haematoxylin, and those for ssDNA with Light Green.

For the detection of apoptotic cells, a double labeling immunohistological stain was performed using a HistostainDS KIT (ZYMED Laboratories, South San Francisco,
U.S.A.). Briefly, for the ssDNA antibody, streptavidin biotin (SAB)-alkaline phosphatase system and BCIP/NTB were used. For CDV-NP, SAB-peroxidase system and hydrogen peroxide/AEC were used.

TUNEL method: The TUNEL method was performed using a system kit (Wako, Osaka, Japan) according to the manufacturers' procedures. Briefly, each of the sections was treated with the provided protein digestion enzyme reagent at $37^{\circ} \mathrm{C}$ for $5-10 \mathrm{~min}$. For labeling DNA-ending, provided $\mathrm{TdT}$ reagent was treated at $37^{\circ} \mathrm{C}$ for $10 \mathrm{~min}$. After the inactivation of endogenous peroxidase, sections were incubated with the provided peroxidase-conjugated antibody at $37^{\circ} \mathrm{C}$ for $10 \mathrm{~min}$. The visualization of the reaction products and counterstain were performed using the same procedure as the ssDNA immunostain.

Electron microscopy: One fresh mediastinal lymph node from an infected dog was selected for ultrastractural examination. One millimeter cubes of a tissue were fixed in $2 \%$ glutaraldehyde and $2 \%$ paraformaldehyde at $4^{\circ} \mathrm{C}$ for $2 \mathrm{hr}$ and then post-fixed in $2 \%$ osmium tetroxide at $4{ }^{\circ} \mathrm{C}$ for $2 \mathrm{hr}$. Each of the samples was en bloc stained with $2 \%$ uranyl acetate at RT for $1 \mathrm{hr}$ and dehyderated through graded alcohols and next propyrene oxide, and embedded in Quetol 812 (NISSIN EM Co., Ltd., Tokyo, Japan). The samples were cut at $0.5 \mu \mathrm{m}$-thickness section and stained with toluidine blue to select for ultrathin. The ultrathin sections were cut at $50 \mathrm{~nm}$-thickness, and collected on 200 mesh copper grids, followed by staining with $2 \%$ uranyl acetate and lead citrate. These sections were examined with a HITACHI H-800 MV transmission electron microscope at $75 \mathrm{kV}$.

Statistical analysis: The CDV-NP positive antigens were scanned as CDV-positive area per a field in $\times 400$ using image-processing software (Win Roof ver 3.1, Mitani corporation, Tokyo, Japan) and calculated the average square for 20 randomly selected fields in the lymphoid follicles. Each section was classified into 4 groups based on the average square: group 1; non-infected dog, group 2; $0 \%$ (no antigens of infected dog), group $3 ;>5 \%$ density of CDVantigens, and group 4; $<5 \% \mathrm{CDV}$-antigens (Fig. 1). The quantitative analysis for ssDNA immunostaining and the TUNEL assay was performed randomly at 40 selected fields in $\times 400$ and counted the ssDNA and TUNEL positive 

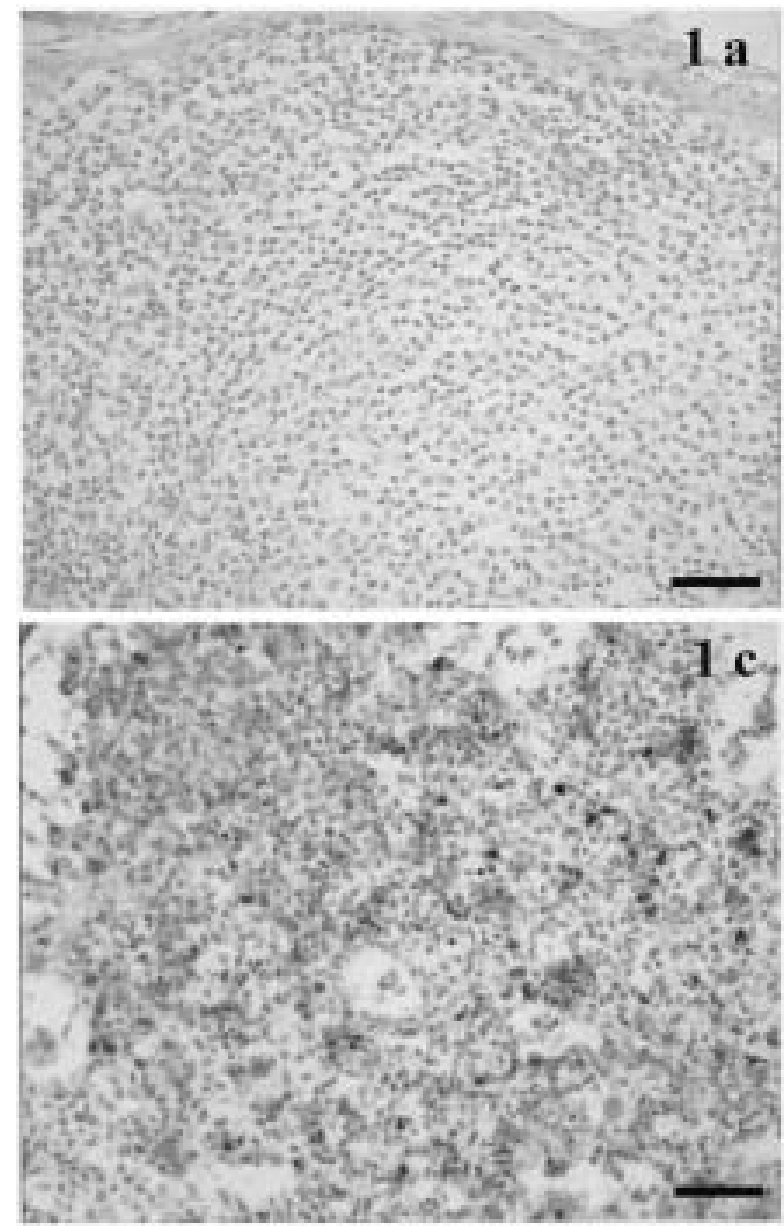

nuclei, respectively. The correlative coefficient between the ssDNA and TUNEL positive cells was evaluated. One-way analysis of variance (ANOVA) was performed to evaluate the significant differences between 4 groups and the number of apoptotic cells visualized by ssDNA or the TUNEL method. The statistical significance was analyzed by Fisher's protected least significant difference method. The $p$-value (a two-sided) of $<5 \%$ was set up to indicate a statistically significant difference.

\section{RESULTS}

Histology and distribution of CDV antigen: The lymphoid tissues from a non-infected dog had well-developed secondary follicles with germinal centers. No CDV-antigens could be detected. The lymphoid tissues of the infected dogs without CDV-antigens (group 2) consisted of small and immature follicles. The border between the cortex and medulla was relatively clear. The medulla of the lymph nodes was slightly expanded with moderate sinus histiocytosis and neutrophilic infiltration.

In the lymph nodes with a large number of CDV-antigens (groups 3 and 4), there was severe to moderate lymphoid depletion. The border between the cortex and medulla was

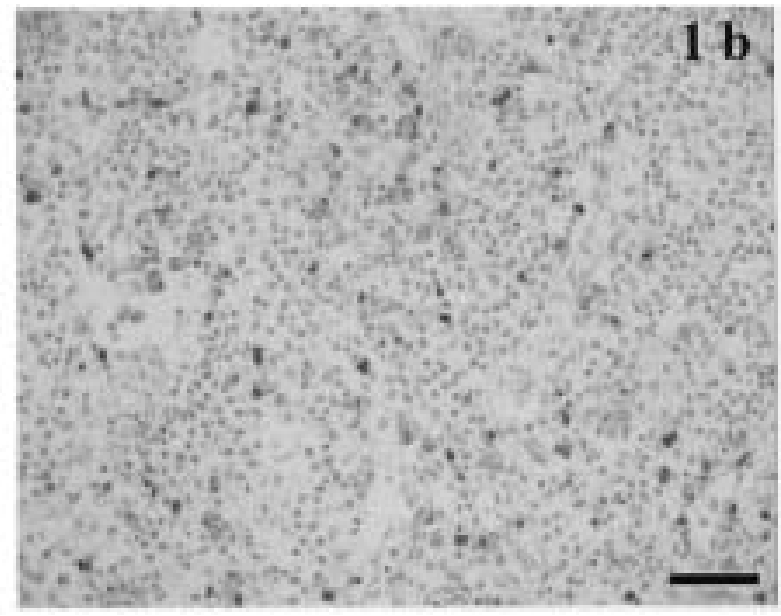

Fig. 1. Immunostaining for monoclonal anti-CDV NP antibody. a; group $2(\mathrm{CDV}$ antigen density $=0 \%)$ : There were no CDV antigens. b; group 3 (CDV antigen density $=4.23 \%$ ): CDV-positive cells were mainly located in macrophage in medullary sinus. c; group 4 (CDV antigen density = $10.99 \%$ ): Many positive cells to CDV are seen diffusely. Bar $=100 \mu \mathrm{m}$.

difficult to distinguish. The medullary sinus was expanded markedly with mild to moderate histiocytosis and mild neutrophilic infiltration. In the lymph nodes with less than $5 \% \mathrm{CDV}$-antigen density (group 3), small amount of viral antigens were located in the macrophages or histiocytes in the medullary regions (Fig. 1b). In the lymph nodes with more than 5\%-CDV antigens (group 4), there was severe sinus histiocytosis, sometimes accompanied by syncytial giant cells. A large number of eosinophilic inclusion bodies were found in the cytoplasm and processes of these histiocytic cells. CDV-antigen was diffusely spread in the survival lymphocytes, histiocytes, macrophages or dendric cells in these lymph nodes.

Apoptosis assay: There was a highly significant correlation in the indexes between ssDNA and the TUNEL assays ( $r=+0.7165$, Fig. 2). In an uninfected dog, ssDNA- or TUNEL-positive cells were localized mainly in the germinal center and paracortical regions. On the other hand, in CDV infected dogs, ssDNA- or TUNEL-positive cells were found in both $\mathrm{T}$ - and B-cell areas, and in even the medulla in various degrees. Positive nuclei for ssDNA and the TUNEL assay were detected in morphologically intact lymphocytes and apoptotic bodies within the cytoplasm of macrophages.

The correlation between the distribution of CDV antigen 


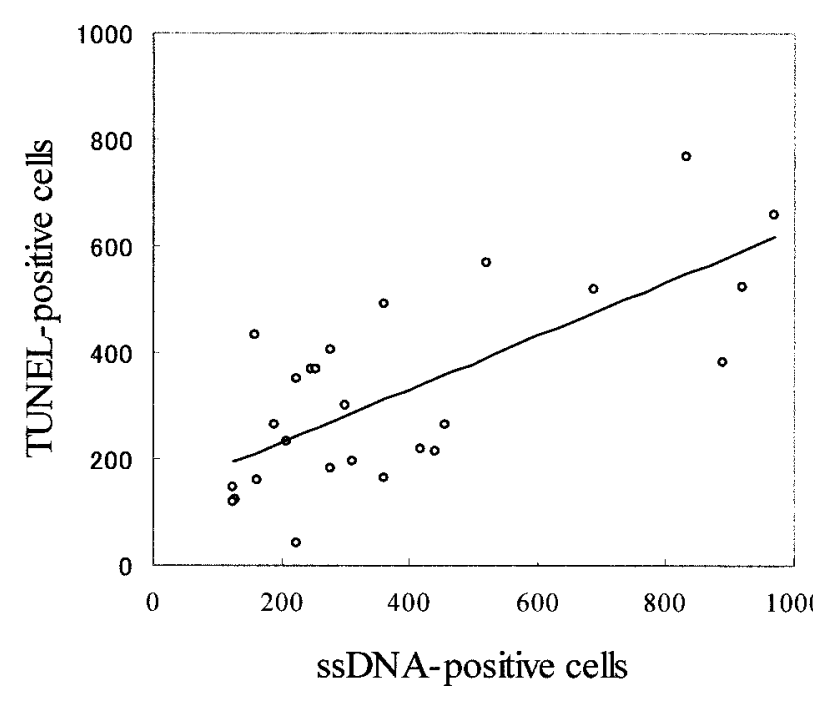

Fig. 2. The correlation of the positive index between immunohistology using monoclonal anti-ssDNA antibody and TUNEL methods. Positive nuclei in both methods were counted in randomly 40 fields at a magnification of $\times 400 . r=+0.7165$.

and apoptotic index was summarized in Fig. 3. ANOVA toward ssDNA immunostain indicated a significant difference between group 2 and $4(P=0.0207)$, and nearly statistical significance between group 1 and $4(P=0.0614)$. The number of positive nuclei in group 3 tended to increase as compared with those in group $2(P=0.0919)$, and slightly increased as compared with those in group 1. Meanwhile the positive count in group 4 for the TUNEL method was statistically significant compared with group $1(P=0.0482)$, and nearly significant with group $2(P=0.0505)$. In group 3 , there was a statistical significance toward group 1 and 2 ( $P=0.0425$ and 0.0377 , respectively).

Double labelling immunostaining: In group 4, a large number of lymphocytes positive for both CDV and ssDNA were detected. The ssDNA positive cells without CDV antigens were also found around ssDNA- and CDV-positive cells. The number of ssDNA (+) / CDV (-) cells was almost equal to those of ssDNA (+) / CDV (+) cells (Fig. 4b). In the group 3, the number of ssDNA (+) and CDV (+) cells was smaller than that of group 4. Moreover, there was a small number of lymphocytes positive for only ssDNA immunostain (Fig. 4a). There were a few CDV-positive macrophages containing ssDNA-positive apoptotic bodies. These macrophages were morphologically easy to distinguish from CDV (+) / ssDNA (+) lymphocytes.

Transmission electron microscopy: In electron microscopic examination, the lymphocytes in the CDV-infected lymph node had several morphological characteristics for apoptosis. Apoptotic lymphocytes showed peripheral crescents of condensed chromatin under the nuclear membrane (Fig. 5a). Phagocytosis of apoptotic lymphocytes was also found within the phagosomes in macrophages (Fig. 5b). Numerous crystalline-arrayed nucleocapsids, approximately $12 \mathrm{~nm}$ in diameter, were found in the cytoplasm of the macrophages (Fig. 5c).

\section{DISCUSSION}

The present study demonstrated a high correlation between the ssDNA-immunostain and TUNEL method employed for the detection of apoptosis or DNA fragmentation [28]. However, these two methods were not always detected in the same regions, and the relationship between intensity of the CDV infections and positive index for those was not statistically equal. Generally, the TUNEL method tends to detect necrotic cells, as well as apoptotic cells, and not to label the early stage apoptosis. Besides, ssDNAimmunostaining was reported to detect the early apoptotic status without a non-specific reaction for necrotic cells [6, 13, 28]. Watanabe et al. [28] described that the positive
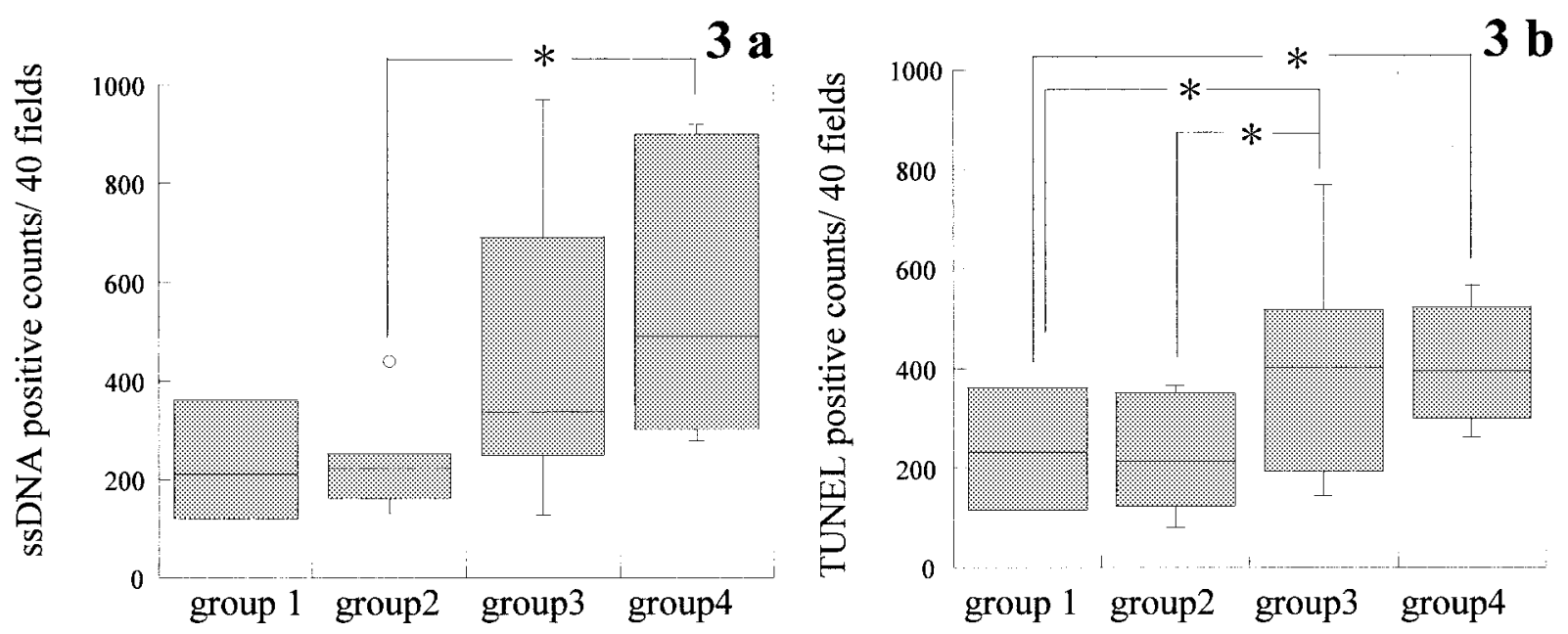

Fig. 3. The correlation between the distribution of CDV antigen and apoptotic index with immunostaining using ssDNA antibody (a) or TUNEL method (b). *; Statistically significant difference $(\mathrm{p}<0.05)$. 

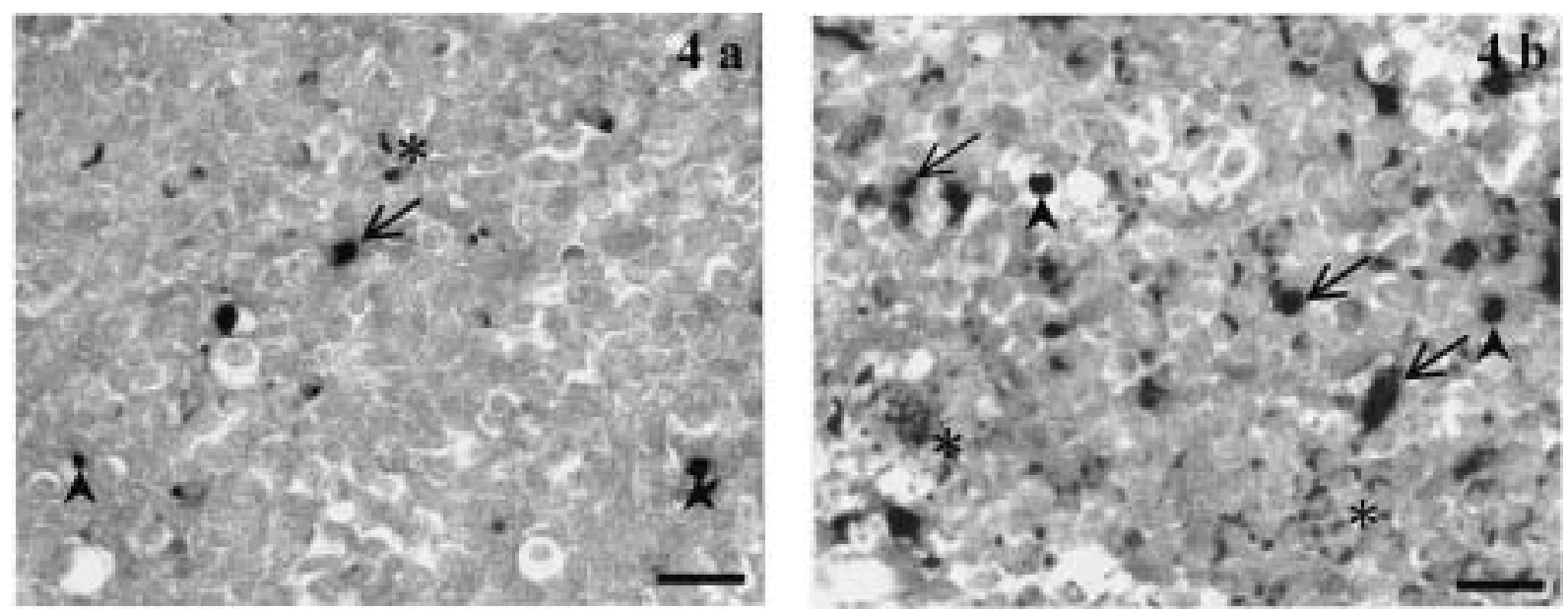

Fig. 4. Double immunostaining for ssDNA and CDV-NP. Apoptotic cells were labeled by BCIP-NTB (shown by arrowhead) and CDV infected cells are labeled by AEC (shown by asterisk). ssDNA (+)/CDV-NP(+) were shown by arrow. a; group 3: mandibular nodes. b; group 4: mandibular nodes. Bar=25 $\mu \mathrm{m}$.

index for TUNEL was commonly higher than that for ssDNA in the same regions of human colorectal carcinomas. Unlikely, positive index for ssDNA-immunostaining was slightly larger than that for the TUNEL method in this study. The reason might be that the necrosis visualized through the TUNEL method more prominently occurred in the colorectal carcinomas than the CDV-infected lymphoid tissues. In addition, early apoptotic stage detectable only by ssDNAimmunostaining might be more frequent in the CDVinfected tissues. Thus, the mAb for ssDNA may be useful to visualize apoptosis in CDV-infected lymphoid tissues. In addition, ultrastractural examination by an electron microscope indicated lymphocytes in the CDV-infected lymph node undergoing the process of apoptosis [2]. Aggregated CDV nucleocapsids $(12 \mathrm{~nm})$ were generally found in the cytoplasm of macrophages. These findings confirmed that the ssDNA and TUNEL results were not false-positive and detected DNA fragmentation.

By using both ssDNA immunostaining and TUNEL method, the incidence of apoptotic cells or DNA fragmentation was statistically higher in group 4 as compared with that in group 2. Concerning the TUNEL method, there was a statistical difference between groups 4 and 1, and between groups 3 and 1 or 2 . These findings indicate that CDV may induce apoptosis in the lymphoid tissues as reported previously $[10,19,25]$. Apoptotic cells might be extensively induced in the lymph nodes by CDV infection. It has been said that CDV infected both T- and B-cell dependent areas and induced notable lymphopenia in the acute or sub-acute phase [15, 18, 31]. In the present study, the CDV-infected lymphoid tissues showed various degrees of lymphoid depletion. These results may indicate CDV-induced apoptosis in lymphocytes turns out the essential factor of immunosuppression in the incipient stage of CDV infection. Even in group 3, the number of apoptotic cells increased in comparison with those in group 1 or 2 , whereas infected cells were mostly macrophages or histiocytes in the medullary sinus. The double labeling immunostain with ssDNA and CDV-NP antibody revealed that the intact non-infected cells adjacent to the ssDNA (+) / CDV (+) lymphocytes also showed apoptosis. In the previous study, it has been considered that viruses such as the human immunodeficiency virus, bovine herpes virus, and MV induce apoptosis in noninfected cells, especially in T cells adjacent to infected cells by a direct or indirect effect $[5,12,22,30]$. Tipold et al. [27] found that cultured mononuclear cells derived from CDV-infected dogs were greatly reduced, in contrast to the infected cells which did not show a very high infection rate. In addition, Okada et al. [21] reported apoptosis-related molecules such as the CD95 (Fas) and TNF-related apoptosis-inducing ligand-receptor were highly expressed on the surface of most surviving non-infected lymphocytes and natural killer cells, increased in number, and activated in the peripheral blood mononuclear cells from MV-patients. The reports suggested the CDV could induce apoptosis not only in infected-cells but also in non-infected cells.

On the other hand, apoptotic cells were detected in the germinal center in group 1 . Group 2 showed approximately the same degree of apoptosis as compared with group 1 . The lymphoid tissues in group 2 had no CDV antigens, and seemed to be repaired as shown by forming immature lymph follicles without the secondary follicles. However, dogs in group 2 were suffering from viremia. In the previous experimental studies $[15,18]$, the evidences of repair as mentioned above were found in 5 weeks after inoculation, but the viremia continued for $8-10$ weeks. The cause of long lasting immunosuppression and viremia may be related to the followings: CD4+ T cell depletion can disturb B cell maturity by depression lymphokines and secondary follicles replacement [11], or lack of mRNA transcript of pro- and anti-inflammatory cytokines in whole blood sample can obstruct directly lymphocyte function in a dog with viremia 


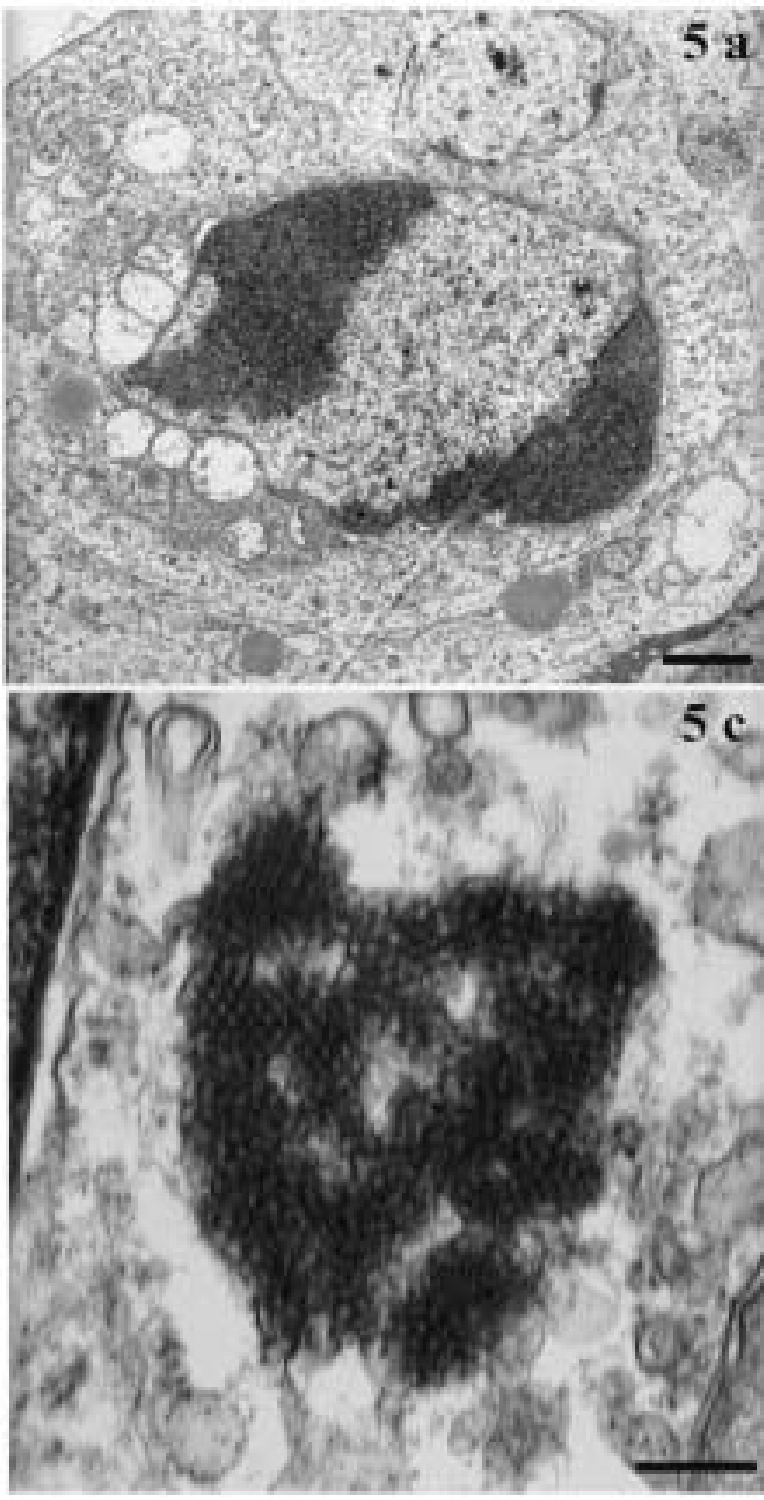

[9]. Similar events may also occur to cause immune suppression and persistent CDV-infection in the dogs of group 2. Recently, it has been suggested MV-induced immunosuppression is due to cell cycle arrest in the $G_{0} / G_{1}$ phase of uninfected lymphocytes after contracted with MV glycoprotein activating on surface of MV-infected cells $[3,16,17$, 20, 26]. The cell cycle arrest is suggested to be associated with low accumulation levels of cyclin D3 and E, low activity of $\mathrm{G}_{1}$ cyclin-dependent kinase, and accumulation of CDK inhibitor, $\mathrm{p} 27^{\mathrm{Kip} 1}$. Thus, a similar phenomenon might be also possible to say for the CDV-infected lymph nodes.

In conclusion, the present study has proved that CDV induces apoptosis in the lymphocytes of infected dogs. In addition, it is implied that CDV seems to cause apoptosis not only in infected cells but also in non-infected cells by certain indirect mechanisms. To elucidate the mechanisms

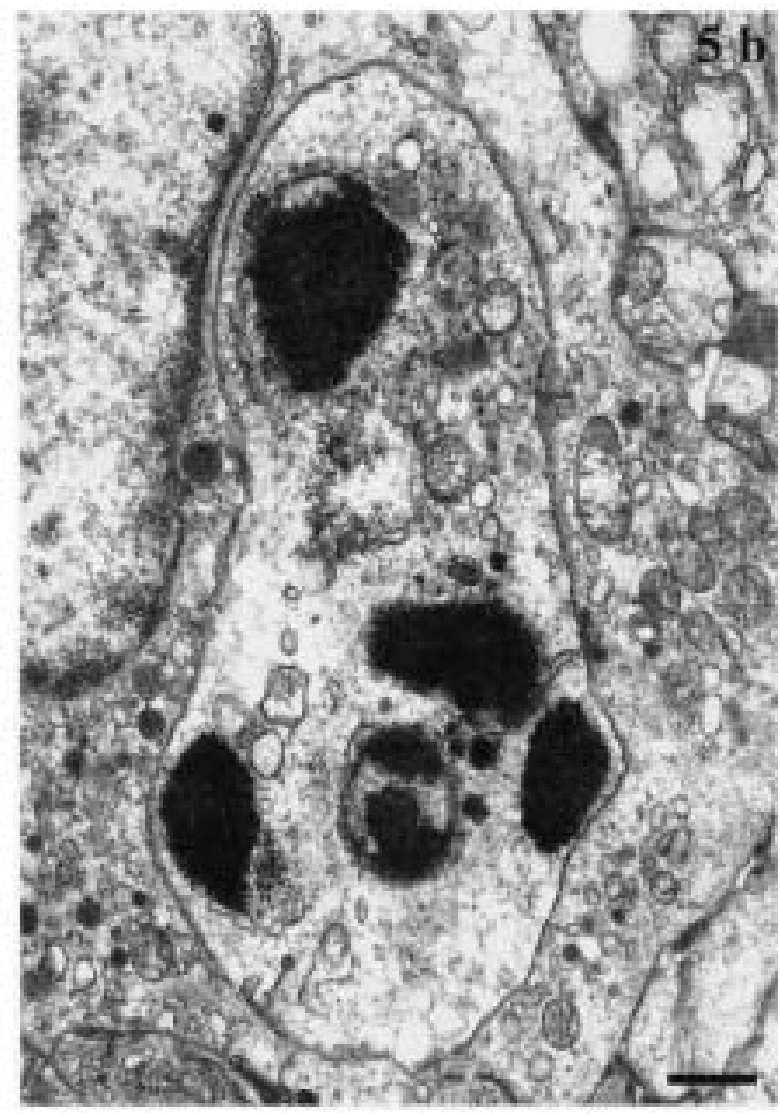

Fig. 5. Electron micrograph of CDV-infected a lymph node. a; Apoptotic lymphocytes showing peripheral crescents of compact chromatin. Bar $=1 \mu \mathrm{m}$. b; Phagosome surrounded by double membranes containing apoptotic nuclei. Bar=1 $\mu \mathrm{m}$. c; Numerous crystalline-arrayed nucleocapsid measuring $12 \mathrm{~nm}$ in diameter in the cytoplasm of macrophages. Bar $=200 \mathrm{~nm}$.

of CDV-associated apoptosis in the lymphoid tissues, especially lymphocytes, and the pathogenesis of lymphoid depletion in CDV-infected dogs, further immunologic investigations will be needed.

\section{REFERENCES}

1. Beckford, A.P., Kashula, R.O.C. and Stephen, C. 1985. Factors associated with fatal cases of measles. S. Afr. Med. J. 68: 858863.

2. Cohen, J.J. 1999. Apoptosis: Mechanisms of life and death in the immuno system. J. Allergy Clin. Immunol. 103: 548-554.

3. Engelking, O., Fedorov, L.M., Lilischkis, R., Meulen, V. and Schneider-Schaulies, S. 1999. Measles virus-induced immunosuppression in vitro is associated with deregulation of $\mathrm{G}_{1}$ cell cycle control proteins. J. Gen.Virol. 80: 1599-1608.

4. Esolen, L.M., Part S.W., Handwich, J.M. and Griffin, D.E. 
1995. Apoptosis as a cause of death in measles virus-infected cells. J. Virol. 69: 3955-3958.

5. Finkel, T.H., Tudor-Williams, G., Banda, M., Cotton, M.F., Curiel, T., Monks,C., Baba, T.W., Ruprecht R.M. and Kupeer A. 1995. Apoptosis occurs predominantly in bystander cells and not in productively infected cells of HIV-and SIV-infected lymph nodes. Nat. Med. Feb. 1: 129-134.

6. Frankfult, O.S., Robb, J.A., Sugarbaker, E.V. and Villa, L. 1996. Monoclonal antibody to single-stranded DNA is a specific and cellular marker of apoptosis. Exp. Cell. Res. 226: 387-397.

7. Fugier-Vivier, I., Servet-Delphrat, C., Rivallier, P., Liu, Y.J. and Rabourdin-Combe, C. 1997. Measles virus suppressed cell-mediated immunity by interfering with the survival and functions of dendritic and T cells. J. Exp. Med. 186: 813-823.

8. Greene, C.E. and Appel, M.J. 1998. Canine distemper. pp. 922. In: Infection Disease of the Dog and Cat, 2nd ed., W.B.Sanunders, Philadelphia.

9. Gröne, A., Frisk A.L. and Baumgärtner, W. 1998. Cytokine mRNA expression in whole blood samples from dogs with natural canine distemper virus infection. Vet. Immunol. Immunopathol. 65: 11-27.

10. Guo, A. and Lu, C. 2000. Canine distemper virus causes apoptosis of Vero cells. J. Vet. Med. Berl. 47: 183-190.

11. Iwatsuki, K., Okita, M., Ochikubo, F., Gemma, T., Shin, Y.S., Miyahima, N., Mikami, T. and Kai, C. 1995. Immunohistochemical analysis of the lymphoid organs of dogs naturally infected with canine distemper virus. J. Comp. Pathol. 113: 185-190.

12. Kaneshima, A.P.G.H., McCure, J.M., Wiegand, G. and Griffin, D.E. 1996. Measles virus infection of thymic epithelium in the SCID-hu mouse leads to thymocyte apoptosis. J. Virol. 70: 3734-3740.

13. Korkolopoulou, P.A., Konstantinidou, A.E., Patsouris, E.S., Christodoulou, P.N., Euphemia, A., Thomas-Tsagli E.A. and Davaris, P.S. 2001. Detection of apoptotic cells in archival tissue from diffuse astrocytomas using a monoclonal antibody to single-stranded DNA. J. Pathol. 193: 377-382.

14. Krakowka, S. 1982. Mechanisms of in vitro immunosuppression in canine distemper virus Infection. J. Clin. Lab. Immunol. 8: $187-196$.

15. Krakowka, S., Higgins, R.J. and Koestner, A. 1980. Canine distemper virus: review of structual and functional modulations in lymphoid tissues. Am. J. Vet. Res. 41: 284-292.

16. McChesney, M.B., Altman, A. and Oldstone, M.B.A. 1988. Suppression of T lymphocyte function by measles virus is due to cell cycle arrest in G1. J. Immunol. 140: 1269-1273.

17. McChesney, M.B., Kehrl, J.H., Valsamakis, A., Fauci, A.S. and Oldstone, M.B.A. 1987. Measles virus infection of B lymphocytes permits cellular activation but blocks progression through the cell cycle. J. Virol. 61: 3441-3447.

18. McCullough, B., Krakowka, S. and Koestner, A. 1973. Experimental canine distemper virus- induced lymphoid depletion. Am. J. Pathol. 74: 155-170.

19. Moro, L., de Sousa Martins, A., de Moraes Alves, C., de
Araujo Santos, F.G., dos Santos Nunes, J.E., Carneiro, R.A., Carvalho, R. and Vasconcelos, A.C. 2003. Apoptosis in canine distemper. Arch. Virol. 148: 153-164.

20. Niewiesk, S., Ohnimus, H., Schnorr, J., Gotzelmann, M., Schneider-Schaulies, S., Jassoy, C. and Meulen, V. 1999. Measles virus-induced immunosuppression in cotton rats is associated with cell cycle retardation in uninfected lymphocytes. $J$. Gen. Virol. 80: 2023-2029.

21. Okada, H., Kobune F., Sato, T.A. Kohama, T., Takeuchi, Y., Abe, T., Takayama, N., Tsuchiya,T. and Tashiro, M. 2000. Expensive lymphopenia due to apoptosis of uninfected lymphocytes in acute measles patients. Arch. Virol. 145: 905-920.

22. Okada, H., Sato, T.A., Katayama, A., Higuchi, K., Shichijo, K., Tsuchiya, T., Takayama, N., Takeuchi, Y., Abe, T., Okabe, N. and Tashiro, M. 2001. Comparative analysis of host responses related to immunosuppression between measles patients and vaccine recipients with live attenuated measles vaccines. Arch. Virol. 146: 859-874.

23. Osterhaus, D.M.E.A., de Swart, R.L., Vos, H.W., Ross, P.S., Kenter, M.J.H. and Barrett, T. 1995. Morbillivirus infection of aquatic mammals: newly identified members of the genus. Vet. Microbiol. 44: 219-239.

24. Schnorr, JJ., Seufert, M., Schlender, J., Borst, j., Johnston, I.C., ter Menlen, V. and Schneider-Schaulies, S. 1997. Cell cycle arrest rather than apoptosis is associated with measles virus contact-mediated immunosuppression in vitro. J. Gen. Virol. 73: 3217-3226.

25. Schobesberger, M., Zurbriggen, A., Summerfield, M. and Griot, C. 1999. Oligodendroglial degeneration in distemper: apoptosis or necrosis? Acta Neuropathol. 97: 279-287.

26. Steven, D.R. and Osburn, B.I. 1976. Immune deficiency in a dog with distemper. J. Am. Vet. Med. Assoc. 168: 493-498

27. Tipold, A., Vandevelde, M., Wittek, R., Moore, P., Summerfield, A. and Zurbriggen, A. 2001. Partial protection and intrathecal invasion of $\mathrm{CD} 8+\mathrm{T}$ cells in acute canine distemper virus infection. Vet. Microbiol. 83: 189-203.

28. Watanabe, I., Toyoda, M., Okuda, J., Tenjo, T., Tanaka, K., Yamamoto, T., Kawasaki, H., Sugiyama, T., Kawarada, Y. and Tanigawa, N. 1999. Detection of apoptotic cells in human colorectal cancer by two different in situ methods: antibody against single-stranded DNA and terminal deoxynucleotidyl transferase-mediated dUTP-biotin nick end-labeling (TUNEL) methods. Jpn. J. Cancer. Res. 90: 188-193.

29. Watanabe, K., Tomiyama, S., Jinnouchi, K. and Yagi, T. 2001. Apoptosis in the hydropic cochlea of the endolymphatic sac: immunohistochemical analysis. Eur. Arch. Otorhinolaryngol. 258: 296-299.

30. Winkler, M.T.C., Doster, A. and Jones, C. 1999. Bovine herpesvirus 1 can infect CD4+ T lymphocytes and induce programmed cell death during acute infection of cattle. J. Virol. 73: 8657-8668.

31. Wunschmann, A., Kremmer, E. and Baumgartner, W. 2000. Phenotypical characterization of $\mathrm{T}$ and B cell areas in lymphoid tissues of dogs with spontaneous distemper. Vet. Iтmиnol. Immunopathol. 73: 83-98. 